RESEARCH ARTICLE

\title{
Does the Opening of a Milk Bank in NICU Cancel the Incidence of NEC?
}

\author{
Quitadamo PA*, Palumbo G, Villani A, Savastano M, Ravidà D, Bisceglia M, Gentile A and Cristalli P \\ NICU “Casa Sollievo della Sofferenza”, San Giovanni Rotondo (FG), Italy
}

“Corresponding author: Quitadamo PA, NICU "Casa Sollievo della Sofferenza”, San Giovanni Rotondo (FG), Italy, Tel: 3394824468, E-mail: pasquaq@tiscali.it

Citation: Quitadamo PA, Palumbo G, Villani A, Savastano M, Ravidà D, et al. (2018) Does the opening of a milk bank in NICU cancel the incidence of NEC? J Pediatr Dis Neonatal Care 1: 104

Article history: Received: 30 January 2018, Accepted: 11 April 2018, Published: 12 April 2018

\begin{abstract}
Several studies suggest that donor milk (DM) is effective in preventing necrotizing enterocolitis (NEC) in preterm infants and DM is widely used for this purpose when the mother's milk (OMM) is unavailable, and the presence of a DMB (Donor Milk Bank) in NICU has indeed increased breast milk feeding.

The underlying cause of NEC is poorly understood but seems multifactorial and is strongly associated with prematurity. The protective effect is likely a result of effects from countless bioactive components and cells that function synergistically to provide multiple levels of protection.

In our experience the availability of DMB in NICU has improved and standardized the use of breast milk and DM for premature babies, using internal protocols and a breastfeeding support practice that has been consolidated over the years.

The present study consists of the assessment of the impact of DMB on the incidence of NEC, intestinal perforation with recourse to surgery, and mortality from NEC in our NICU. We compared the data related to two distinct periods, pre and post activation of the DMB: the years 2006 to 2011 versus the years 2012 to 2016.

The population includes 372 very low birth weight infants (VLBW). We observed a reduction of $53 \%$ in the incidence of NEC, $86 \%$ of the recourse to surgery and $58 \%$ of mortality in the second rather than the first period in question, with total reset of all three entries in the years 2015-2016, where no case of NEC was observed in the VLBW. The comparison between the numbers of transferred infants for surgery in the two periods indeed has a statistical significance.

Our experience is further evidence of the protective role of human milk on NEC and supports the recommendations that encourage its wide use in NICU.

It also confirms that the existence of the internal guide grafting favors the use of breast milk and DM in NICU.
\end{abstract}

Keywords: Necrotizing Enterocolitis; Prevention of NEC; Human Milk Bank; Human Milk; Feeding preterm

List of Abbreviations: NEC: Necrotizing Enterocolitis; DMB: Donor Milk Bank; OMM: Own Mother's Milk ;VLBW: Very Low Birth Weight; DM: Donor Milk; HM: Human Milk; VON: Vermont Oxford Network; SIN: Società Italiana di Neonatologia

\section{Introduction}

The food of choice for premature infants is their own mother's milk, however in cases where it's not obtainable, such as before it becomes available or when it's no longer available donated human milk is used instead.

Donor milk is widely used to prevent necrotizing enterocolitis for vulnerable premature infants when OMM is unavailable and several studies suggest that DM is just as effective in preventing NEC in preterm infants [1-8].

The first association in between of the use of human milk and the NEC dates back to 1973, since then the bibliographic entries have been increasingly numerous and today the protective effect of human milk against the NEC is considered acquired data.

In a recent multicenter study involving 1587 infants with a birth weight of less than $1250 \mathrm{~g}$, those being extremely preterm who had received an exclusive human milk (HM) diet showed a significantly lower incidence of NEC and further demonstrating multiple improved outcomes after implementation of such a feeding protocol [9].

In a population-based cohort study, the availability of DHM has been associated with positive changes including decrease in NEC rates and increased breast milk feeding [10]. 
Lower rates of NEC and mortality have been observed for the category of infants who received HM for more than $50 \%$ of the hospital days, compared with infants who received human milk for fewer than 50\% of hospital days [11]. Implementing an EHM diet in VLBW infants has led to a significant decrease in the incidence of NEC in another retrospective study and the incidence of NEC is lower after the establishment of the milk bank in yet another study $[12,13]$.

In the current literature there is little data on the type of nutrition for the preterm infants and in particular on the use of donated human milk. A study of VLBW identified that only 30\% of mothers were able to cover their infants' nutritional needs during hospitalization in TIN [14].

Where there is a tradition or culture for breastfeeding and milk donation, mother's milk or human milk feeding rates are much higher with better VLBW performance in terms of neonatal morbidity and mortality $[15,16]$.

\section{Human milk and NEC}

The underlying cause of NEC is poorly understood but seems multifactorial and is strongly associated with prematurity. Specifically the genesis of NEC is not yet well known but the pathophysiology of NEC is well explained in a paper that deepens the aspect of the susceptibility of preterm infants to NEC [17]. It is known that the immaturity of their gastrointestinal tract is manifested in multiple ways: reduced gastric proteolytic enzymes, increate gastric $\mathrm{pH}$, decreased intestinal motility, increate intestinal permeability, altered epithelial membrane tight junctions, diminished intestinal mucus coat $[18,19]$.

Intestinal mucosal injury and inflammation as well as the presence of abnormal intestinal colonization contribute to NEC development [20].

Some studies on intact bovine protein have shown that this produces the traces of NEC in animal models [21].

To this must be added the exposure to pathogens of NICU that may not be held into consideration because of their associated immature mucosal immune system [22]. In this review it is also mentioned that these factors create an environment leading to milk stasis, bacterial overgrowth, gut barrier failure and subsequent invasion of bacteria, which lead to an uncontrolled inflammatory response. The protective effect is likely a result of effects from countless bioactive components that function synergistically to provide multiple levels of protection from NEC, including immunomodulatory, anti-infective, antioxidant, growth-promoting and gut-colonizing effects, such as epidermal growth factor, nucleotides and glutamine which stimulate intestinal maturity, and through its bactericidal, immunologic, antioxidant and anti-inflammatory properties such as commensal bacteria, oligosaccharides, cytokines, platelet-activating factor acetyl hydrolase, a major trigger in the uncontrolled inflammation of NEC, lysozyme, lactoferrin, transforming growth factors and stem cells, which likely counteract the risk factors for NEC [23-27].

In a systematic review it is also declared that many results suggest that protection against NEC may also be done dependently and the greatest protective effect is obtained with consumption of more than $50 \%$ of the total feeds [28].

\section{Our experience}

The availability in our NICU of DHM has increased and has standardized the use of breast milk and DM for premature babies, using internal protocols and a breastfeeding support practice that has been consolidated over the years. In our DHM the availability of HM has increased over time.

In detail, the bank's activities began in the final months of 2010 and all the procedures referred to the guidelines of the SIN, which regulate the management of a milk bank in Italy in addition to the HCCP system.

In the following years a departmental procedure was developed that is suitable for the context and it includes an early and systematic compression scheme of the breast after premature delivery, a protocol for the administration of minimal enteral feeding, a scheme of reduction or suspension of feeding enteral in case of food intolerance, based on criteria that evaluate the quantity and type of gastric stagnation, a feeding scheme through gavage, a scheme of fortification of the mother's milk or bank to the suspension of parental nutrition, and a systematic collection of milk composition data using MIRYS tools, evaluating the macronutrient content of human milk (protein, carbohydrates, lipids, calories). In addition, the practice of prescribing the diet with the milk bank has been standardized until breast milk becomes available for infants weighing less than 1800 grams and on the judgment of the prescriber for premature babies weighing more than 1800 grams or with pathologies.

The scheme is described as 12 feedings in 24 hours up to a weight of 1250 grams and then 8 feedings when a weight of more than 1250 grams is reached.

The prescription is carried out every morning by the doctor before the end of the night watch, assisted with the staff of the DHM, after the assessment of food tolerance, abdominal objectivity and clinical conditions.

Every woman who gives birth prematurely is approached in the first hours after birth to be educated on the importance of breast milk for her premature child and on how to pull milk according to the defined pattern. No drop of extracted milk is wasted. This organization of work schedules has allowed us to observe important progress in feeding the premature babies, with even exceptional cases of mothers who have managed to feed extensively premature babies, even twins, and even to donate very significant quantities of milk to the DHM. 
The more extensive use of a human or mother's milk has reduced the incidence of some complications of prematurity, starting with the NEC.

Since we do not have a neonatal surgery department in our Institute, we are forced to transfer premature infants with this type of pathology. It's for this reason that our sensitivity towards this fearful complication is particularly marked. We questioned if the opening of the DHM had modified the clinical course of the VLBW, precisely with respect to the incidence of this serious affection of premature birth.

\section{The study}

It consists of the assessment of the impact of DHM on the incidence of NEC, intestinal perforation with recourse to surgery and mortality from NEC in our NICU.

\section{Materials and methods}

We compared the data related to two distinct periods, pre and post activation of the DHM.

The first period includes the years 2006 to 2011 and the second period the years 2012 to 2016 .

The population includes 369 VLBW (preterm that have died due to other causes have been excluded).

We evaluated the number of NEC diagnosed year by year in the context of the VLBW assisted in our NICU, the number of newborns transferred to Pediatric Surgery and the number of premature infants who died due to NEC. We combined the data for each year in two groups: 2006-2011 and 2012-2016.

A statistical confrontation of the data has been done on account of the incidence of the three considered variables observed in the two periods of pre and post activation of the DMB (Table 2,3 and 4). Therefore, the 3 variables studied are: the number and the percentages of NEC diagnosed, of infants transferred for surgery and of newborns deceased with NEC. They are all VLBW babies.

A Fisher's exact probability Test was performed to check it there was a statistical significance.

The test is significant if $\mathrm{p}<0.05$. We evaluated the size effect $\mathrm{V}$ di Cramer to understand if the insignificance of the comparison between several variables could have been affected by the size of the sample.

\section{Results}

In the first group the incidence of NEC was 7.65\% with 18 diagnoses, the percentage of transfer due to surgery was $5.1 \%$ with 12 infants transferred, and the percentage of those killed by NEC was $4 \%$ ( 4 deceased babies for NEC). In the second group the percentages were respectively of $3.6 \%$ with 5 NEC diagnosed, and $0.72 \%$ with 1 surgery and 1 NEC fatality (Table 1 ).

\begin{tabular}{|c|c|c|c|}
\hline & $\mathbf{2 0 0 6 - 2 0 1 1}$ & $\mathbf{2 0 1 2 - 2 0 1 6}$ & P value \\
\hline $\mathrm{N}^{\circ}$ VLBW & 231 & 138 & \\
\hline $\mathrm{N}^{\circ}$ NEC & $18(7,65 \%)$ & $5(3,6 \%)$ & 0.109 \\
\hline $\begin{array}{c}\mathrm{N}^{\circ} \text { infants transferred } \\
\text { to surgery }\end{array}$ & $12(5,1 \%)$ & $1(0,72 \%)$ & 0.037 \\
\hline $\begin{array}{c}\mathrm{N}^{\circ} \text { infants died for } \\
\text { NEC }\end{array}$ & $4(1,7 \%)$ & $1(0,72 \%)$ & 0.654 \\
\hline
\end{tabular}

Table 1: The Incidence of NEC in the First and Second group

We observed a reduction of 53\% in the incidence of NEC, $86 \%$ of the recourse to surgery and $58 \%$ of mortality in the second rather than the first period in question, with total reset of all three entries in the years 2015-2016, where no case of NEC was observed in the VLBW.

If we separate the data by year, the worst numbers were observed in 2007 where 37 VLBW were admitted with 5 NEC (15.15\%), 2 transferred (6\%) and 2 (6\%) deceased, and the best in 2016 and 2017 with no case of NEC.

A statistical confrontation of the data has been done on account of the incidence of the three considered variables observed in the two periods of pre and post activation of the DMB and detailed in the Tables 1,2,3 and 4.

In Table 2 there is no significant relationship between the two variables being analyzed (incidence of NEC and opening of the milk bank).

\begin{tabular}{|c|c|c|c|c|c|}
\hline & value & gl Chi-square test \\
\hline & $2,569^{\mathrm{a}}$ & 1 & $\begin{array}{c}\text { Asymptotic } \\
\text { significance } \\
\text { (bilateral) }\end{array}$ & $\begin{array}{c}\text { Exact Sign. } \\
\text { (bilateral) }\end{array}$ & $\begin{array}{c}\text { Exact. Sign } \\
\text { (unilateral) }\end{array}$ \\
\hline Pearson Chi-square & 1,905 & 1 & 0.109 & & \\
\hline $\begin{array}{c}\text { Continuity } \\
\text { Correction }^{\mathrm{b}}\end{array}$ & $1,0.167$ & & \\
\hline
\end{tabular}




\begin{tabular}{|c|c|c|c|c|c|}
\hline \multicolumn{2}{|c|}{ A: Chi-square test } \\
\hline & value & gl & $\begin{array}{c}\text { Asymptotic } \\
\text { significance } \\
\text { (bilateral) }\end{array}$ & $\begin{array}{c}\text { Exact Sign. } \\
\text { (bilateral) }\end{array}$ & $\begin{array}{c}\text { Exact. Sign } \\
\text { (unilateral) }\end{array}$ \\
\hline Likelhood ratio & 2,772 & 1 & 0.096 & & \\
\hline Fisher exact Test & & 1 & 0.109 & & 0.081 \\
\hline Bylinear association & 2,562 & 124 & \\
\hline N valid casis & 369 & & & & \\
\hline
\end{tabular}

a- 0 cells $(0,0 \%)$ have an expected count of less than 5 . Free minimum predicted count is 8,60 .

b- Only for table $2 \times 2$

\begin{tabular}{|c|c|c|c|}
\hline \multicolumn{3}{|c|}{ B: Simmetrical Measures } \\
\hline \multirow{2}{*}{ Nominal for nominal } & Value & $\begin{array}{c}\text { Approxiimate } \\
\text { Significance }\end{array}$ \\
\cline { 2 - 4 } & Phi & -.083 & .109 \\
\cline { 2 - 4 } & $\begin{array}{c}\text { Cramer V } \\
\text { Contingency } \\
\text { Coefficient }\end{array}$ & .083 & .109 \\
\hline \multicolumn{2}{|c|}{ N of valid cases } & 369 & .109 \\
\hline
\end{tabular}

The test didn't result significant when $\mathrm{p}=0.109$ through the ChiQuadro test. It would be interesting to analyze a larger sample as the Cramer size effect $\mathrm{V}$ would be equal to 0.083 , in other words a larger entità

Table 2: Incidence of NEC

The test didn't result significant when $\mathrm{p}=0.109$ through the ChiQuadro test. It would be interesting to analyze a larger sample as the Cramer size effect $\mathrm{V}$ would be equal to 0.083 , in other words a larger entity.

The correlation between the third variable, and therefore the number of deceased infants due to NEC between 2006 to 2001 and 2012 to 2016 after the opening of the bank, didn't result statistically significant even though it verified an important reduction percentage-wise of death by NEC (Table 3 ).

\begin{tabular}{|c|c|c|c|c|c|}
\hline \multicolumn{7}{|c|}{ A: Chi-square test } \\
\hline & value & gl & $\begin{array}{c}\text { Asymptotic } \\
\text { significance } \\
\text { (bilateral) }\end{array}$ & $\begin{array}{c}\text { Exact Sign. } \\
\text { (bilateral) }\end{array}$ & $\begin{array}{c}\text { Exact. Sign } \\
\text { (unilateral) }\end{array}$ \\
\hline Pearson Chi-square & $.655^{\mathrm{a}}$ & 1 & .418 & & \\
\hline $\begin{array}{c}\text { Continuity } \\
\text { Correction }\end{array}$ & .119 & 1 & .731 & & \\
\hline Likelhood ratio & .719 & 1 & .396 & & .382 \\
\hline Fisher exact Test & & & & .654 & \\
\hline Bylinear association & .654 & 1 & .419 & & \\
\hline N valid casis & 369 & & & & \\
\hline
\end{tabular}

a- 2 cells (50\%) have an expected count of less than 5 . Free minimum predicted count is 1,7 .

b- Only for table $2 \times 2$

\begin{tabular}{|c|c|c|c|}
\hline \multicolumn{3}{|c|}{ B: Simmetrical Measures } \\
\hline \multirow{2}{*}{} & Phi & Value & $\begin{array}{c}\text { Approxiimate } \\
\text { Significance }\end{array}$ \\
\hline \multirow{3}{*}{ Nominal for nominal } & Cramer V &. .042 & .418 \\
\cline { 2 - 4 } & $\begin{array}{c}\text { Contingency } \\
\text { Coefficient }\end{array}$ & .042 & .418 \\
\hline \multicolumn{2}{|c|}{ N of valid cases } & 369 & .418 \\
\hline
\end{tabular}

The test didn't result significant when $\mathrm{p}=0.654$ through the ChiQuadro test

It would be interesting to analyze a larger sample as the Cramer size effect $\mathrm{V}$ would be equal to 0.042 , a moderate size

Table 3: VLBW deceased with NEC

The test didn't result significant when $\mathrm{p}=0.654$ through the exact Fisher test, it would be interesting to analyze a larger sample as the Cramer size effect $V$ would be equal to 0.042 : a moderate size effect.

The association between the $n^{\circ}$ of transferred infants for surgery in the two periods has indeed a statistical significance (Table 4). 


\begin{tabular}{|c|c|c|c|c|c|}
\hline \multicolumn{2}{|c|}{ A: Chi-square test } \\
\hline & value & gl & $\begin{array}{c}\text { Asymptotic } \\
\text { significance } \\
\text { (bilateral) }\end{array}$ & $\begin{array}{c}\text { Exact Sign. } \\
\text { (bilateral) }\end{array}$ & $\begin{array}{c}\text { Exact. Sign } \\
\text { (unilateral) }\end{array}$ \\
\hline Pearson Chi-square & $5.079^{\mathrm{a}}$ & 1 & .024 & & \\
\hline $\begin{array}{c}\text { Continuity } \\
\text { Correction }\end{array}$ & 3.849 & 1 & .050 & & \\
\hline Likelhood ratio & 6.336 & 1 & .012 & & .018 \\
\hline Fisher exact Test & & & & .037 & \\
\hline Bylinear association & 5.065 & 1 & .024 & & \\
\hline N valid casis & 369 & & & & \\
\hline
\end{tabular}

a- 1 celle (25\%) have an expected count of less than 5 . Free minimum predicted count is 4.86 b- Only for table $2 \times 2$

\begin{tabular}{|c|c|c|c|}
\hline \multicolumn{3}{|c|}{ B: Simmetrical Measures } \\
\hline \multicolumn{2}{|c|}{} & Value & $\begin{array}{c}\text { Approxiimate } \\
\text { Significance }\end{array}$ \\
\hline \multirow{2}{*}{ Nominal for nominal } & Phi & -.117 & .024 \\
\cline { 2 - 4 } & \begin{tabular}{c} 
Cramer V \\
Contingency \\
\cline { 2 - 4 }
\end{tabular} & .117 & .024 \\
\hline \multicolumn{2}{|c|}{ Noefficient } & .117 & .024 \\
\hline
\end{tabular}

The test is significant $\mathrm{p}<0.05(\mathrm{p}=0.037)$ with Fisher's exact Test.

There is a significative relationship between "Opening of the milk bank" and Transfer at Surgery ward, $\mathrm{X} 2=(1, \mathrm{~N}=369)=5.079, \mathrm{p}=0.024$.

VLBW without "Human Milk Bank" are more likely engage in trasfer at surgery ward then VLBW in Human Milk Bank period (5.2\% to 0.7\%).

Cramer's $\mathrm{V}=0.117=>$ there is a very small effect size on our study.

Table 4: Transfer for Surgery

The test is significant $\mathrm{p}<0.05$ ( $\mathrm{p}=0.037$ ) with Fisher's exact Test. There is a significate relationship between "Opening of the milk bank" and Transfer at Surgery ward, $\mathrm{X}^{2}=(1, \mathrm{~N}=369)=5.079, \mathrm{p}=0.024$.

VLBW without "Human Milk Bank" are more likely engage in transfer at surgery ward then VLBW in Human Milk Bank period $(5.2 \%$ to $0.7 \%)$.

Cramer's $V=0.117=>$ there is a very small effect size on our study.

This is an important result for us, because it's an aspect of assistance that particularly concerns us.

\section{Discussion}

We compared the incidence data of NEC, transfers to Pediatric Surgery and of mortality for NEC related to two periods: the years from 2006 to 2011 and the years from 2012 to 2016. The difference in the assistance given to the VLBW in the two periods relates to the type of feeding that transitioned from maternal milk /formula to maternal milk/ to donor milk with a gradual transition. At the same time the management of nutrition of premature babies has also improved. Therefore the focus is on evaluating if the increased widespread use of human milk for VLBW in our NICU has translated into reduced morbidity and mortality for NEC.

The comparison showed a 53\% reduction in the incidence of NEC, $86 \%$ in the use of surgery for NEC and 58\% in mortality from NEC. The statistical significance was observed within the comparison concerning the need for transfer by surgery, a crucial aspect for the NICU that does not have a neonatal surgery department within the same hospital. Another noteworthy finding is the total elimination of NEC diagnoses in the last few years included in the study.

For the other variables such as incidence and mortality it would be productive if we had a more broad range of samples since to analyze as a high value in the first case and a moderate value in the second would generate a more numerically significant correlation between the two using larger values.

A multicenter study could allow this result.

This work confirms the literature data on significant reductions in the incidence of NEC with the implementation of the use of human milk; however, it also focuses on the utility of the presence of a milk bank as an integral part of the NICU, which is a very interesting aspect indeed [1-15].

Moreover, if we consider the cost of the care of premature babies with clinical or surgical NEC, the savings are quite extensive.

We are aware of the paucity of the numbers when dealing with data from a single NICU center, however, this study is strongly indicative of the protective effect of the diet with human milk against the NEC and, truthfully, the ultimate goal of this scientific contribution is the promotion of the widespread use of mother and human milk in NICU. It's a crucial objective. 
In 1979 Cunningham MD wrote that "Closer study of premature infants has led to the establishment of human milk as the recommended nutritional standard for them. Infants fed with human milk are found to gain protection against necrotizing enterocolitis, and have fewer upper respiratory tract infections and systemic infections" and that "the authors favor the use of human milk for premature infants". However, in 2018 the authors still wrote scientific articles attaining to human milk and necrotizing enterocolitis, and they still have objectives similar to "to review the known and potential protective factors in human milk that may reduce NEC, the data that support a protective benefit of mother's own milk, pasteurized donor human milk, and an "all-human" diet and the evidence for practical implementation of human milk in the NICU"; as we ourselves discuss this in the present article [29]. There is something incomprehensible. What was changed in 40 years? indicative of the protective effect of the diet with human milk against the NEC and, truthfully, the ultimate goal of this scientific contribution is the promotion of the widespread use of mother and human milk in NICU. It's a crucial objective.

The truth is that the incidence of NEC has gradually decreased over the past 10 years and one key strategy directed at preventing the onset of NEC has been providing human milk feeding to preterm infants. But we believe it is a completely inadequate result on the subject of feeding with human milk, given the important discoveries that have occurred in this period of time which have involved human milk, as well as the ease of disseminating information online throughout the internet and therefore, the world [30-33].

It is not conceivable that in this era, where advanced biological technologies have highlighted hundreds of factors present in human milk and millions of cells, with an inimitable ability to exerting beneficial effects on the short and long term health of our newborn, that the use of human breast milk is still not a widespread practice in NICU [34-44]. Now we have the tools to understand the basis of Professor Julius Hess' statement written in 1922: “The best results are obtained from premature infants $<1500$ grams when they are fed human milk". The important acquisitions make breast milk indispensable and irreplaceable for all newborns but especially for premature babies for whom the contribution of maternal stem cells could be the fundamental element to accelerate the development of various organs.

The rates of consumption of human milk in the present day are unsatisfactory.

\section{Conclusion}

This study shows that the presence of a milk bank in TIN can result in a marked reduction in the incidence of NEC, intestinal perforation and mortality for NEC, thanks to the more widespread and codified use of human milk in nutrition of the VLBW.

The association between the number of transferred infants for surgery in the two periods, pre and post activation of the DHM, has indeed a statistical significance.

Our experience is further evidence of the protective role of human milk on NEC and supports the recommendations that encourage its wide use in NICU.

It also confirms that the existence of the internal guide grafting favors the use of breast milk and DM in NICU.

The important decrease of incidence of NEC until the total reset and the significant reduction in the use of surgery in recent years, when the DHM has become an integral part of the NICU, has become a reality that gives us enthusiasm and motivation in pursuing this goal.

The promotion of breastfeeding and the culture of human milk donation represent a global health priority, taking into consideration their social implications and positive effects on the whole planet.

\section{References}

1) de Halleux V, Pieltain C, Senterre T, Rigo J (2017) Use of donor milk in the neonatal intensive care unit. Semin Fetal Neonatal Med 22: 23-9.

2) Chowning R, Radmacher P, Lewis S, Serke L, Pettit N, et al. (2016) A retrospective analysis of the effect of human milk on prevention of necrotizing enterocolitis and postnatal growth. J Perinatol 36: 221-4.

3) Cortez J, Makker K, Kraemer DF, Neu J, Sharma R, et al. (2017) Maternal milk feedings reduce sepsis, necrotizing enterocolitis and improve outcomes of premature infants. J Perinatol 38: 71-4.

4) Patel AL, Panagos PG, Silvestri JM (2017) Reducing Incidence of Necrotizing Enterocolitis. Clin Perinatol 44: 683-700.

5) Patole SK, Klerk ND (2005) Impact of standardised feeding regimens on incidence of neonatal necrotising enterocolitis: a systematic review and meta-analysis of observational studies. Arch Dis Child Fetal Neonatal Ed, 90: F147-51.

6) Buckle A, Taylor C (2017) Cost and Cost-Effectiveness of Donor Human Milk to Prevent Necrotizing Enterocolitis: Systematic Review. Breastfeed Med 12: 52836.

7) Rozé JC, Ancel PY, Lepage P, Martin-Marchand L, Al Nabhani Z, et al. (2017) Nutrition EPIPAGE 2 study group and the EPIFLORE Study Group. Nutritional strategies and gut microbiota composition as risk factors for necrotizing enterocolitisin very-preterm infants. Am J Clin Nutr 106: 821-30.

8) Herrmann K, Carroll K (2014) An exclusively human milk diet reduces necrotizing enterocolitis. Breastfeed Med. 9: 184-90.

9) Hair AB, Peluso AM, Hawthorne KM, Perez J, Smith DP, et al. (2016) Beyond Necrotizing Enterocolitis Prevention: Improving Outcomes with an Exclusive Human Milk-Based Diet. Breastfeed Med 1: 70-4.

10) Kantorowska A, Wei JC, Cohen RS, Lawrence RA, Gould JB, et al. (2016) Impact of Donor Milk Availability on Breast Milk Use and Necrotizing Enterocolitis Rates. Pediatrics 137: e20153123. 
11) Meinzen-Derr, B. Poindexter, L. Wrage, Morrow AL, Stoll B, et al. (2009) Role of human milk in extremely low birth weight infants' risk of necrotizing enterocolitis or death. J Perinatol 29: 57-62.

12) Assad M, Elliott MJ, Abraham JH (2016) Decreased cost and improved feeding tolerance in VLBW infants fed an exclusive human milk diet. J Perinatol 36: 216-20.

13) Larena Fernández I, Vara Callau M, Royo Pérez D, López Bernués R, Cortés Sierra J, et al. (2015) Study of the effects of the implementation of a human milk donor bank in preterm newborns in Aragon. Enferm Clin 25: 57-63.

14) Schanler, R.J, Lau, C, Hurst, N.M, and Smith E.O. Randomized trial of donor human milk versus preterm formula as substitutes for mothers' own milk in the feeding of extremely premature infants. Pediatrics 116: 400-6

15) Healy DB, Brennan AM, O’Donovan R, Daly V, Doolan A, et al. (2016) Structured promotion of breastmilk expression is associated with shortened hospitalisation for very preterm infants. Acta Paediatr 105: e252-6.

16) Cortez J, Makker K, Kraemer DF, Neu J, Sharma R, et al. (2018) Maternal milk feedings reduce sepsis, necrotizing enterocolitis and improve outcomes of premature infants. J Perinatol 38: 71-4.

17) Maffei D, Schanler RJ (2017) Human milk is the feeding strategy to prevent necrotizing enterocolitis! Semin Perinatol 41: 36-40.

18) Shulman, RJ, Schanler RJ, Lau C, Heitkemper MA, Ou CN, and Smith EO (1998) Early feeding, antenatal glucocorticoids, and human milk decrease intestinal permeability in preterm infants. Pediatr Res 44: 519-23.

19) Morriss FH, Moore M, Gibson T, West MS (1990) Motility of the small intestine in preterm infants who later have necrotizing enterocolitis. J Pediatr 117: S20-3.

20) Warner BB, Deych E, Zhou Y, Hall-Moore C, Weinstock GM, et al. (2016) Gut bacteria dysbiosis and necrotising enterocolitis in very low birthweight infants: a prospective case-control study. Lancet 387: 1928-36.

21) Di Lorenzo M, Bass J, Krantis A (1995) An intraluminal model of necrotizing enterocolitis in the developing neonatal piglet. J Pediatr Surg 30: 1138-42.

22) Dvorak B, Halpern MD, Holubec H, Williams CS, McWilliam DL, et al. (2002) Epidermal growth factor reduces the development of necrotizing enterocolitis in a neonatal rat model. Am J Physiol Gastrointest Liver Physiol 282: G156-64.

23) Dicky O, Ehlinger V, Montjaux N, Gremmo-Féger G, Sizun J, et al. (2017) Policy of feeding very preterm infants with their mother's own fresh expressed milk was associated with a reduced risk of bronchopulmonary dysplasia. Acta Paediatr 106: 755-62.

24) Hansen LW, Yang WL, Bolognese AC, Jacob A, Chen T, (2017) et al. Treatment with milk fat globule epidermal growth factor-factor 8 (MFG-E8) reduces inflammation and lung injury in neonatal sepsis. Surgery 162: 349-57.

25) Patel AL, Kim JH (2018) Human milk and necrotizing enterocolitis. Seminars in Pediatric Surgery 27: 34-8.

26) Collado MC, Santaella M, Mira-Pascual L, Martínez-Arias E, Khodayar-Pardo P, et al. (2015) Longitudinal study of cytokine expression, lipid profile and neuronal growth factors in human breast milk from term and preterm deliveries. Nutrients 7: 8577-91.

27) Caplan MS. Paediatrics: Are human milk oligosaccharides the magic bullet for necrotizing enterocolitis? Nat Rev Gastroenterol Hepatol 14: $394-5$.

28) Corpeleijn WE, de Waard M, Christmann V, van Goudoever JB, Jansen-van der Weide MC, et al. (2016) Effect of Donor Milk on Severe Infections and Mortality in Very Low-Birth-Weight Infants: The Early Nutrition Study Randomized Clinical Trial. JAMA Pediatr 170: 654-61.

29) Patel AL, Kim JH (2018) Human milk and necrotizing enterocolitis. Semin Pediatr Surg 27: 34-8.

30) Witkowska-Zimny M, Kaminska-El-Hassan E (2017) Cells of human breast milk. Cell Mol Biol Lett 22: 11.

31) Briere CE, McGrath JM, Jensen T, Matson A, Finck C (2016) Breast Milk Stem Cells: Current Science and Implications for Preterm Infants. Adv Neonatal Care 16: 410-9.

32) Hassiotou F, Hartmann PE (2014) At the dawn of a new discovery: the potential of breast milk stem cells. Adv Nutr 5: 770-8.

33) Rath EM, Duff AP, Håkansson AP, Vacher CS, Liu GJ, et al. (2015) Structure and Potential Cellular Targets of HAMLET-like Anti-Cancer Compounds made from Milk Components. J Pharm Pharm Sci 18: 773-824.

34) Poindexter B (2017) The direct and indirect influence of own mother's milk on bronchopulmonary dysplasia and costs. Arch Dis Child Fetal Neonatal Ed 102: F192-3.

35) Dicky O, Ehlinger V, Montjaux N, Gremmo-Féger G, Sizun J, et al. (2017) Policy of feeding very preterm infants with their mother's own fresh expressed milk was associated with a reduced risk of bronchopulmonary dysplasia. Acta Paediatr 106: 755-62.

36) Patel AL, Johnson TJ, Robin B, Bigger HR, Buchanan A, et al. (2017) Influence of own mother's milk on bronchopulmonary dysplasia and costs. Arch Dis Child Fetal Neonatal Ed 102: F256-61.

37) Cortez J, Makker K, Kraemer DF, Neu J, Sharma R, et al. (2018) Maternal milk feedings reduce sepsis, necrotizing enterocolitis and improve outcomes of premature infants. J Perinatol 38: 71-4.

38) Kim JI, Kim BN, Kim JW, Hong SB, Shin MS, et al. (2017) Breastfeeding is associated with enhanced learning abilities in school-aged children. Child Adolesc Psychiatry Ment Health 11: 36.

39) Bernard JY, Armand M, Peyre H, Garcia C, Forhan A, De Agostini M, Charles MA, et al. Breastfeeding, Polyunsaturated Fatty Acid Levels in Colostrum and Child Intelligence Quotient at Age 5-6 Years. J Pediatr 183: 43-50.

40) Wong PD, Birken CS, Parkin PC, Venu I, Chen Y, et al. (2017) Total Breast-Feeding Duration and Dental Caries in Healthy Urban Children. Acad Pediatr 17: $310-5$.

41) Poudel RR, Shrestha D (2016) Breastfeeding for diabetes prevention. J Pak Med Assoc 66: S88-90.

42) Kalra B, Gupta Y, Kalra S (2015) Breast feeding: preventive therapy for type 2 diabetes. J Pak Med Assoc 65: 1134-6.

43) Yakubov R, Nadir E, Stein R, Klein-Kremer A (2015) The Duration of Breastfeeding and Its Association with Metabolic Syndrome among Obese Children. The Scientific World Journal 2015: 731319.

44) Madore LS, Bora S, Erdei C, Jumani T, Dengos AR, et al. (2017) Effects of Donor Breastmilk Feeding on Growth and Early Neurodevelopmental Outcomes in Preterm Infants: An Observational Study. Clin Ther 39: 1210-20. 